This paper is published as:

Druckman, A. and T. Jackson (2008). "Measuring resource inequalities: the concepts and methodology for an area-based Gini coefficient." Ecological Economics 65(2): 242-252.

http://dx.doi.org/10.1016/i.ecolecon.2007.12.013

\title{
Measuring resource inequalities: the concepts and methodology for an area-based Gini coefficient
}

\author{
Druckman, A. and Jackson, T. \\ ESRC Research Group on Lifestyles, Values and Environment (RESOLVE) \\ University of Surrey, Guildford, GU2 7XH UK
}

\author{
Correspondence address: \\ Angela Druckman \\ Centre for Environmental Strategy \\ University of Surrey \\ Guildford GU2 7XH \\ UK \\ Tel: $+44(0) 1483686679$ \\ Fax: $+44(0) 1483876671$ \\ Email: a.druckman@surrey.ac.uk
}

\begin{abstract}
Although inequalities in income and expenditure are relatively well researched, comparatively little attention has been paid, to date, to inequalities in resource use. This is clearly a shortcoming when it comes to developing informed policies for sustainable consumption and social justice. This paper describes an indicator of inequality in resource use called the AR-Gini. The AR-Gini is an area-based measure of resource inequality that estimates inequalities between neighbourhoods with regard to the consumption of specific consumer goods. It is also capable of estimating inequalities in the emissions resulting from resource use, such as carbon dioxide emissions from energy use, and solid waste arisings from material resource use. The indicator is designed to be used as a basis for broadening the discussion concerning 'food deserts' to inequalities in other types of resource use. By estimating the AR-Gini for a wide range of goods and services we aim to enhance our understanding of resource inequalities and their drivers, identify which resources have highest inequalities, and to explore trends in inequalities. The paper describes the concepts underlying the construction of the AR-Gini and its methodology. Its use is illustrated by pilot applications (specifically, men's and boys' clothing, carpets,
\end{abstract}


refrigerators/freezers and clothes washer/driers). The results illustrate that different levels of inequality are associated with different commodities. The paper concludes with a brief discussion of some possible policy implications of the AR-Gini.

Keywords: sustainable consumption; household consumption; equity; indicators.

\section{Introduction}

In this paper the concept and methodology for an area-based indicator of inequalities in resource use is described. The indicator, called the AR-Gini, enables exploration of inequalities in resource use between neighbourhoods. It can be applied to a wide variety of goods, from household fuel use, to various categories of food consumption such as meat, fish or vegetables, or purchases of consumer goods such as clothing, furniture and domestic appliances. It can also be applied to emissions arising as a result of resource use, such as carbon dioxide emissions due to energy consumption and solid waste arisings as a result of clothing and food consumption. The AR-Gini can thus be used to extend the debate concerning food deserts ${ }^{1}$ (Clarke et al. 2004; Guy et al. 2004) to a wide variety of other kinds of area-based resource and associated emissions inequalities. This will lead us to a greater understanding of the extent to which there are "pockets of deprivation" with respect to specific resources. By providing a measure of inequality we can identify the commodities in which inequalities are most extreme, and model trends in inequalities. Use of the AR-Gini will help us to understand the drivers of inequalities.

The AR-Gini is based on the conventional Gini coefficient, which is a commonly used measure of income inequality (Barr 1998). Other studies have adapted the Gini coefficient to measure energy resource inequality. However, as far as the authors of this paper are aware, no other studies have been carried out to date to estimate Gini-based inequalities for other resources. Furthermore, the area-basis of the AR-Gini is believed to be a novel development. It measures inequalities between small local geographical areas and this is of particular relevance to policy-makers, as sustainable development strategies are often best pursued at local area or community level.

\footnotetext{
${ }^{1}$ A basic definition of 'food deserts' is that they are 'areas of relative exclusion where people experience physical and economic barriers to accessing healthy food’ (Shaw 2006:231).
} 
Study of the environmental impact of household consumption requires analysis of a broad range of impact categories such as global warming potential, stratospheric ozone depletion, acidification and eutrophication (see, for example, UNEP (2003)). A life cycle perspective is required to ensure that all impacts that occur from 'cradle to grave' are included. A large number of studies have been carried out on this topic and the reader is referred to Tukker and Jansen (2006) and Hertwich (2006) for comprehensive reviews. The methodology developed for the AR-Gini is capable of estimating inequalities in resource use from a life cycle perspective. A full-resource version based on input-output analysis is currently under development. This full-resource version will include upstream or 'embedded' resource use (and emissions) incurred during production of consumer goods and services. The purpose of this paper is to describe the concept and methodology of the AR-Gini, and for demonstration purposes, we show how the AR-Gini can be applied to specific direct resource uses. The example in this paper therefore takes a stream-lined approach to environmental assessment based on the principles of material flow analysis (Todd and Curran 1999; Matthews et al. 2000; Bringezu and Moriguchi 2002).

Estimation of the AR-Gini is based on results from the Local Area Resource Analysis (LARA) model developed at the University of Surrey (Druckman and Jackson 2007b; Druckman and Jackson 2007a; Druckman et al. 2007). LARA estimates the average resource use of households grouped by small socio-economically homogeneous geographical areas for various commodities, such as energy use, meat consumption and clothing. It can also be used to estimate the mean emissions that result from resource use such as, for example, carbon dioxide emissions due to energy use and packaging waste arisings due to, for example, food consumption. As such LARA is able to provide estimates of global warming potential using, say, carbon dioxide as a proxy indicator, or to be used for local waste management planning. In order to illustrate the basis of the data on which estimation of the AR-Gini is calculated a brief description of LARA's methodology and some sample outputs from LARA are given in this paper. Other papers give a more detailed explanation of LARA's methodology and further examples its outputs (Druckman and Jackson 2007b; Druckman and Jackson 2007a; Druckman et al. 2007). 
The paper is organised as follows. In the next section we present the background to the development of the AR-Gini. The methodology section follows and is in two parts: first the methodology for LARA, the underlying model, is presented in Section 3.1, as this lays the foundations for understanding the AR-Gini. Next the methodology for calculating the AR-Gini itself is described in Section 3.2. The major assumptions and limitations are discussed in Section 3.3. Results and discussions are presented in Section 4. First, sample outputs from LARA for selected commodities ('Household Appliances' and 'Carpets') for two local areas representing extreme deprivation and affluence are shown in Section 4.1. This provides a good groundwork for presenting Lorenz curves and pilot estimates of the AR-Gini for selected commodities (Carpets', 'Clothes Washer/Driers', 'Refrigerators, Freezers \& Fridge Freezers', and 'Men's and Boys' Garments') in the following section (Section 4.2). The paper concludes by summarising the contribution the AR-Gini may make to enhancing our understanding of resource inequalities along with a brief discussion concerning possible implications of the AR-Gini for sustainable development policy-making. A glossary of terms is placed after the conclusion.

\section{Background}

Policy-makers face two major objectives (amongst others) in the sustainable development arena. The first is to live within the environmental limits of the planet, and to achieve this policies must be devised to reduce resource use and production of wastes (Weizsacker et al. 1996; Adriaanse et al. 1997; Matthews et al. 2000; HM Government 2005). The second is that policies should aim to reduce social and environmental injustice (Stymne and Jackson 2000; HM Government 2005; Stern 2006). These twin principles are enshrined in the Bruntland definition of sustainable development (WCED 1987). In order to address these objectives robust information on inequalities in resource use and associated emissions is vital to enable policy-makers to understand distributions, and to use this information and the understanding it brings as a basis for devising sustainable development policies.

Achieving both these objectives simultaneously may present hidden challenges, as the relationship between inequality and environmental degradation caused by resource use and the associated emissions is complex. One school of thought suggests that higher equity tends to produce higher environmental quality (Boyce 1994; Bimonte 2002). Contrarily, other investigations have found that this is not necessarily the case, and that there is a potential trade-off between equality and environmental quality 
(Scruggs 1998; Magnani 2000; Heerink et al. 2001). Thus we cannot say, with certainty, that increased equity and reduced environmental degradation go hand in hand. A full investigation into this is beyond the scope of the paper, and this is a topic for further research. Nevertheless it is clear that we need to develop our understanding of existing inequalities in resource use and associated emissions to be able to answer the following questions: To what extent do area-based inequalities exist? In which commodities are the inequalities greatest? What are the current trends? Answers to these questions may also be used as a basis for enhancing our understanding of the drivers behind the inequalities.

A commonly used measure of income inequality is the Gini coefficient (Ruitenbeek 1996; Fernandez et al. 2005; Jacobson et al. 2005; Bosi and Seegmuller 2006). A Gini coefficient of 1 represents absolute inequality, and a Gini coefficient of 0 represents perfect equity ${ }^{2}$. The Gini coefficient has the advantage over other measures of equity such as the Variance indicator because it is independent of absolute values and compares each value not to the mean but to every other value (Barr 1998). The most severe draw-back of the Gini coefficient is that it is possible to have two economies that have the same Gini coefficient but have different income distributions. In such cases it is possible to reach different conclusions concerning their levels of inequality depending on the relative weight that is allocated to low income groups compared with higher income groups. This ambiguity occurs when the Lorenz curves intersect. Atkinson (1983) devised a measure of inequality to overcome this difficulty. Atkinson's index considers distributional aspects explicitly, and can be interpreted as both an inequality measure and as an index of the potential welfare gains from redistribution (Barr 1998). The Atkinson index introduces an explicit parameter $(\varepsilon)$ that represents the weight attached by society to inequality in the distribution. $\varepsilon$ ranges from zero, which means that society is indifferent about the distribution, to infinity, which means that society is concerned only with the position of the lowest income group (Atkinson 1983: page 56). The difficulty with operationalising the Atkinson index is that the value for $\varepsilon$ relies on value judgements, and empirical data on which to base appropriate vales for $\varepsilon$ are sparse (Stymne and Jackson 2000). Atkinson (1983) suggests that the value for $\varepsilon$ should be found through a 'mental experiment' in which the desirability of redistribution of income is assessed (Atkinson 1983: page 58).

\footnotetext{
${ }^{2}$ It is, in theory, possible to have a negative Gini coefficient. When applied to incomes (as is normally the case), the Gini coefficient cannot be negative as negative incomes are not (generally) recorded. However, if it is applied to a value that can itself be negative, such as climate change impacts, then negative values of the Gini coefficient are possible (Tol et al. 2004).
} 
In this study we follow the approach used by Jacobson et al (2005) who used the Gini coefficient in conjunction with the Lorenz curve. We assume that in cases where Lorenz curves do not intersect, the Gini coefficient gives an unambiguous measure of inequality (Atkinson 1983). Choice of using the Gini coefficient in conjunction with the Lorenz curve over using Atkinson's index has the advantage of a conceptually simpler, better known and more transparent measure, that gives unambiguous results as long as the Lorenz curves do not intersect.

A criticism of both the Gini coefficient and the Atkinson index is that they only include the formal economy and thus environmental goods and services such as forest use are omitted (Ruitenbeek 1996). Ruitenbeek (1996) devised an "ecologically sensitive" Gini coefficient ("ESGINI") that takes account of traditional ecological services as well as formal monetary income. His empirical analysis demonstrated that the ESGINI provides a more complete picture of inequality, showing that levels of inequality are found to be lower when environmental services such as forest use are accounted for than when inequality measures are based solely on monetary income. He went on to show that income support programs targeted at conventional cash crops may increase inequality.

The Gini coefficient is generally applied to measure income inequality, and has been widely used, for example, to inform policy-making in developing countries, and to study the impact of income inequality on health. It has been used explicitly in relation to sustainable development for example, in an assessment of the income distribution impacts of a carbon tax in the USA (Oladosu and Rose 2007). The Gini coefficient has been extended from its measurement of income inequality to study expenditure inequality by Goodman and Oldfield (2004). Goodman and Oldfield argue that expenditure inequality tends to reflect long-run or lifetime differences in people's circumstances, whereas income inequality has greater short-term volatility. This is because people counteract fluctuations in income by saving when income is relatively plentiful and using savings when income is relatively lean. A worrying counter argument to this is that households are increasingly maintaining living standards by incurring debt (Department of Trade and Industry 2005), and therefore inequalities based on expenditure patterns may be masking underlying increases in inequality. 
Studies have been carried out concerning inequalities in direct and indirect energy demand (Herendeen 1974; Kok et al. 2003; Papathanasopoulou and Jackson 2007). For example Papathanasopoulou and Jackson (2007) investigated the degree of fossil resource inequality between income quintiles in the UK between 1968 and 2000 using a Gini coefficient of fossil resource inequality for direct and indirect fossil resource use. Their results show that the Gini coefficient for total fossil resource consumption grew by $24 \%$ over the time period. By comparison the Gini coefficient for overall household expenditure rose by only $13 \%$. They found that the increase in resource inequality was prompted by the rising demand by high income quintiles for goods and services such as: "fuel \& light" (heating and lighting the home), "car use" (private transportation), "recreation", "travel" and "other services". Their analysis showed further that the Gini coefficient for "direct" fossil resources ("fuel \& light" and "car use") was lower and rose less steeply than the Gini coefficient for fossil resources embodied in other goods and services (indirect fossil resource requirements). From this they concluded that policy initiatives to reduce fossil resource requirements (and the associated climate change impacts) must pay careful attention to distributional differences. Furthermore, they surmised that the "fuel poverty" debate in the UK and elsewhere - which currently focuses exclusively on household fuels - needs widening. In particular, they concluded that attention also needs to be paid to the inequalities associated with the indirect fossil resources embedded in other goods and services.

Saboohi (2001) studied inequalities in energy consumption between rural and urban neighbourhoods in Iran. He calculated separate Gini coefficients to demonstrate the rural/urban dichotomy with relation to energy consumption. He concluded that eliminating energy subsidies may have a serious impact on the living standards of low income households and on households in rural areas. Fernandez et al (2005) estimated Gini coefficients for energy consumption for different segments of the population of a rural Indian village. Jacobson et al (2005) used the Lorenz curve and the Gini coefficient to compare the distribution of energy consumption in five countries (Norway, USA, El Salvador, Thailand and Kenya), They found a dramatic range of energy distributions, with far lower levels of inequality in electricity consumption in some industrialised nations than others, and with industrialising countries having generally higher inequality than industrialised countries. 
Other uses have been made of the Gini coefficient in the environmental field. For example Tol et al (2004) developed a Gini coefficient for global climate change impacts. They predicted that climate change impacts will cause increasing inequalities in the near future, and the situation will continue to deteriorate for more than a century before stabilising at a more egalitarian level.

From this review we can see that the Gini coefficient is increasingly being applied to non-monetary inequalities, and especially to inequalities in energy consumption. However, an indicator of inequalities in non-energy resource use has not, as far as the authors are aware, yet been developed. The AR-Gini fills this gap as it can be applied to a wide range of resources and their associated emissions. The extension of the Gini coefficient to an area basis has been carried out in this project because many strategies aimed at reducing resource demand are best pursued at the level of geographical areas or social communities. A specific example where area-based policies are of particular importance is local waste management. The AR-Gini can be applied to assess inequalities in waste arisings in order to inform waste reduction strategies such as incremental charging for waste collection.

\section{Methodology}

Calculation of the AR-Gini is based on results from LARA, and therefore the Methodology section starts with a description of the LARA model. A description of the AR-Gini's methodology then follows. More detailed descriptions of LARA, its limitations and examples of its results may be found elsewhere (Druckman et al. 2005; Druckman and Jackson 2007a; Druckman and Jackson 2007b; Druckman et al. 2007).

\subsection{Local Area Resource Analysis (LARA)}

The aim of LARA is to estimate the annual average resource use of small geographical areas by calculating the average quantity of resources and associated emissions purchased by each area's households. The outputs of LARA are informative in their own right and can be used as a basis for other applications. One example application is to estimate local area household waste arisings in England and Wales (Druckman and Jackson 2007a; Druckman et al. 2007). Another application is calculation of the AR-Gini, which is the subject of this paper. 
For the purposes of LARA and its applications (including the AR-Gini), local areas are defined as Output Areas (OAs) as used in the UK 2001 Census. OAs are the highest level of geographical detail available from the UK 2001 Census. They are small areas of approximately 124 households on average, that are as socially homogeneous as possible, based on tenure of household and dwelling type ${ }^{3}$ (Office for National Statistics 2006). LARA uses the UK 2001 Census definition of a household unit, which defines a household as "one person living alone, or, a group of people living at the same address with common housekeeping - that is, sharing either a living room or at least one meal a day" (Office for National Statistics 2001).

A simplified system diagram of LARA is shown in Figure 1. The approach adopted is to compute average annual household spending of a local Output Area (OA). This expenditure is converted into resource use using price/weight conversion data. Expenditure data are obtained from the UK Expenditure Survey, which is a survey of a random sample of private households in the United Kingdom carried out annually by the Office for National Statistics (Office for National Statistics 2005). The smallest geographic unit for which data from this are made available are Government Office Regions (GORs), of which there are nine England ${ }^{4}$. As household expenditure is not measured routinely at local area level, we are faced with the challenge of estimating expenditure data for small local areas from national survey data. This is an example of a "small area estimation" problem, in which direct data for a small area (known as a domain) are not available, and therefore national survey data are combined with an auxiliary data source to build a modelled relationship (Heady et al. 2003; Rao 2003). The methodology developed in LARA may be classified as an "Indirect Domain Estimation” approach (Rao 2003).

Figure 1 shows that, in order to estimate average household expenditure in each local area, the modelled relationship developed in LARA combines data from the UK Expenditure Survey, a national dataset, with UK 2001 Census data, which is used as the auxiliary dataset. Socio-economic and demographic characteristics of households in each local area are found from the Census. The average expenditure of households with matching socio-economic characteristics is then calculated from the Expenditure Survey, and thus average household expenditure in each local area is determined.

\footnotetext{
${ }^{3}$ In England and Wales there are 175,434 OAs (Office for National Statistics 2006)

${ }^{4}$ See http://www.statistics.gov.uk/geography/gor.asp.
} 
The next step is to calculate mass of resource use from the expenditures already calculated by using price information. If required, emissions arising as a result of resource use (such as carbon dioxide emissions due to energy use) can then be calculated using appropriate intensity factors as explained in Druckman and Jackson (2007b). Price information is obtained from a variety of sources depending on the commodity in question. For example, for energy consumption data from $\mathrm{DTI}^{5}$, Sutherland (SALKENT) Tables ${ }^{6}$, EnergyWatch ${ }^{7}$ and $\mathrm{BRE}^{8}$ are used; for food data from Family Food ${ }^{9}$ are used. In this paper we illustrate use of LARA for 'Household Appliances' and 'Carpets' using UK Trade Data ${ }^{10}$. This selection has been made purely to demonstrate the methodology, and no attempt has been made to represent the whole range of goods purchased by households.

As stated in the Introduction, LARA can take a life-cycle perspective to include direct and indirect resource flows. Direct resource flows are the flows that are physically demanded by the households of neighbourhoods under study, whereas indirect resource flows are upstream resources required to produce goods and services (Rosenblum et al. 2000; Eurostat 2001). In the current version, direct resource flows only are considered and the pilot estimates of the AR-Gini shown given in this paper are for direct resource inequalities. Work is currently being carried out on a version of LARA that will model total (direct and indirect) resource flows using input-output analysis (Miller and Blair 1985; Hertwich 2006; Jackson et al. 2006), and from this an AR-Gini from a life-cycle perspective will be estimated.

LARA is able to estimate the mean resource use and associated emissions for every small geographical Output Area (OA) in England and Wales, and examples of outputs from LARA for various different types of areas are shown elsewhere (Druckman et al. 2005; Druckman and Jackson 2007a; Druckman and Jackson 2007b; Druckman et al. 2007). In this paper one set of example results is shown for illustrative purposes. In this example two contrasting OAs are selected according to the Index of

\footnotetext{
${ }^{5}$ See http://www.dti.gov.uk/energy/statistics/publications/prices/index.html

${ }^{6}$ See http://www.sutherlandtables.co.uk/

${ }^{7}$ See http://www.energywatch.org.uk/

${ }^{8}$ See http://www.bre.co.uk/

${ }^{9}$ See http://statistics.defra.gov.uk/esg/publications/efs/default.asp

${ }^{10}$ Available from /www.uktradeinfo.com/
} 
Multiple Deprivation (IMD) 2004. The IMD measures deprivation based on performance in seven domains: income; employment; health and disability; education, skills and training; barriers to housing and services: living environment; and incidence of recorded crime in the area (Office of the Deputy Prime Minister 2004). The two case study OAs selected are within the lowest and highest $1 \%$ respectively on the IMD scale, and average resource use due to 'Clothes Washer/Driers' and 'Carpets' in these two areas is estimated. These results are compared to estimates of the mean household resource use in England and Wales. This illustration has been included to help the reader appreciate the type of outputs produced by LARA, the model under-lying the AR-Gini.

\subsection{AR-Gini}

The study in this paper extends the use of the Gini coefficient by demonstrating a methodology for calculating the Area-based Resource Gini (AR-Gini) coefficient which is a measure of resource inequalities by area. The AR-Gini differs from the conventional Gini coefficient in two ways. First, it is a measure of inequality in terms of mass of resources instead of being a monetary measurement; in other words, it reflects resource inequalities in society. The second way in which the AR-Gini differs from the conventional Gini is that it is calculated on an area-basis, giving a measure of inequality by comparing the resource uses of neighbourhoods, whereas the conventional Gini compares on a household or per capita basis. Table 1 summarizes the differences between the AR-Gini and the conventional Gini.

The Gini coefficient, which is originally applied to incomes, is measured as "half of the arithmetic average of the absolute differences between all pairs of relative incomes, the total being normalized on mean income" (Barr 1998: page 151). An easier way to explain the Gini coefficient is to draw a graphical representation using the Lorenz curve, as shown in Figure 2. The Lorenz curve is a plot of cumulative household income against cumulative population. In a totally equitable society, $50 \%$ of the population would have $50 \%$ of total income (represented by point $\mathrm{P}$ on the graph), and the income distribution would be given by straight line $\mathrm{AB}$. In a less equitable society, income distribution may be represented by curve AQB; in this case $50 \%$ of the population may have, say, just $15 \%$ of total income. The shaded area is a measure of the extent of inequality in income: the larger the shaded area the higher the inequality. The Gini coefficient is calculated as the ratio of the shaded area to the area of triangle $\mathrm{ABC}$. 
The Gini coefficient for income is formally calculated using the equation

$$
G=\frac{1}{2 n^{2} \eta} \sum_{i=1}^{n} \sum_{j=1}^{n}\left(y^{i}-y^{j}\right)
$$

where $y^{i}$ and $y^{j}$ are the incomes of the ith and jth household, $\eta$ is average income, and there are $n$ households (Barr 1998). When the formula is adapted to calculate the AR-Gini $y^{\mathrm{i}}$ and $\mathrm{y}^{\mathrm{j}}$ represent average resource use in the ith and jth Output Areas, $n$ is the number of Output Areas, and $\eta$ is average resource use across all Output Areas. The Lorenz curve is drawn by ranking the mean resource use of each Output Area and plotting the proportion of cumulative mean Output Area resource use against the cumulative proportion of the number of Output Areas. As explained in Section 2, we assume that if the Lorenz curves do not intersect then the AR-Gini coefficient gives an unambiguous measure of inequality.

For illustrative purposes, in this paper we draw Lorenz curves and estimate the AR-Gini for selected consumer commodities ('Carpets', 'Clothes Washer/Driers', 'Refrigerators, Freezers \& Fridge Freezers', and 'Men's and Boys' Garments'). This selection is purely to demonstrate that different consumer commodities have different inequalities, and that the AR-Gini is capable of quantifying these inequalities. We also estimate an area-based expenditure Gini for 'Total Expenditure', and compare it with a household-based Gini coefficient for 'Total Expenditure'. Estimation of the AR-Gini requires data to be available for calculation of resource use using LARA for every Output Area in England and Wales. However, at the time the work was carried out, the complete dataset from the Census covering all England and Wales at Output Area level was unavailable. Therefore a dataset at a less detailed geographical level has been used to demonstrate the methodology. The dataset used covers England and Wales at Ward level. Wards are larger than Output Areas and are not socio-economically homogeneous ${ }^{11}$. Therefore, using Wards instead of Output Areas leads to a loss in the level of detail of pockets of extreme deprivation and extreme affluence that can be identified using the model, and in future work it is intended to calculate the AR-Gini on Output Area basis.

\footnotetext{
${ }^{11}$ There are 8,800 Wards in England and Wales compared to 175,434 Output Areas.
} 


\subsection{Assumptions \& Limitations}

The AR-Gini is based on national, accredited UK databases. In this paper it has been demonstrated by estimating resource inequalities for the years 1996/7 to 2003/4 based on expenditure data from the Expenditure Survey which is carried out annually. Household characteristics data are taken from UK Census 2001. The UK Census is carried out at 10 year intervals, and the study period start year of 1996 is the midpoint between the 1991 and 2001 Census. The 2001 Census is considered the most complete and reliable socio-economic dataset that is available in the UK, providing an incomparable depth of information with comprehensive geographical coverage (Vickers et al. 2005). In this study we assume that the general socio-economic hierarchy of geographic areas is relatively static throughout the study period $^{12}$.

The transferability of LARA and the AR-Gini to other countries depends on the availability of appropriate datasets. Most countries carry out comprehensive expenditure surveys similar to the UK Expenditure Survey on an annual basis. The important feature of UK Census 2001 that has enabled this project to achieve such high levels of socio-economic and geographical disaggregation is the design of Census Output Areas to have maximum socio-economic homogeneity. Successful transferability of the methodology to other countries depends on the availability census data on a similar homogenous basis. Small areas grouped together purely on the basis of proximity may be used: they would produce results that could be expected to rank resource inequalities for specific commodities in correct order but the levels of inequality would be reduced in comparison to calculation on a homogenous area basis.

LARA is based on data from the Expenditure Survey, which covers consumer commodities purchased in exchange for money that are declared by households that take part in the Expenditure Survey. Therefore the study includes resource use that is recorded as part of the formal economy but excludes commodities that enter households through informal means (Alexander 2006). This means that gifts and, for example, goods such as children's clothes that are frequently passed between households without payment, are excluded from the study, as are also, of course, goods acquired through the black market. Goods and services provided by the environment, such as forest use, are also excluded from this study. Furthermore, the Expenditure Survey currently fails to distinguish between 'environmentally

\footnotetext{
${ }^{12}$ For a further discussion of this the reader is referred to Druckman and Jackson (2007a).
} 
friendly' goods (such as energy saving light bulbs) and their standard equivalent, and therefore the ARGini cannot be used to explore inequalities for such categories.

The sample size of the Expenditure Survey limits the level of resource disaggregation that is possible to be achieved. In the pilot results the AR-Gini has been averaged over years 2000/01 to 2003/04; this is because the sample size of the Expenditure Survey is not large enough to give reliable results from LARA for each year individually at this level of commodity detail for certain commodities. The survey size particularly limits analysis of relatively infrequently purchased commodities such as household appliances, whereas analysis of more frequently purchased commodities, such as clothing, is less limited. Resource use due to relatively infrequently purchased commodities must therefore be averaged over several years, or commodities must be grouped into highly aggregated categories. In order to provide meaningful time series results for a wide range of commodities for highly disaggregated commodity categories, the sample size of the Expenditure Survey needs to be considerably larger.

In the examples presented in this paper we use average price per unit weight for all items within one commodity category. For the types of goods covered in this paper it is hard to estimate the direction of any bias that may arise due to this. On the one hand, use of average price per unit weight may cause resource use in affluent neighbourhoods to be over-estimated, as residents of these areas may purchase a high proportion of luxury goods. Conversely, residents of affluent areas tend to be mobile and have good access to information. They are therefore able to purchase goods at competitive prices, whereas residents in deprived areas tend to have less access to affordable goods. This issue is discussed in greater depth in Druckman et al (2007). For the specific examples illustrated here, identifying the price paid by specific socio-economic groups is a complex task and has not been attempted. However, it is possible to overcome this shortcoming for certain types of resources. For example, in the application of LARA to household energy use, a matrix to match various energy tariffs to each case in the Expenditure Survey was developed. For further details of this the reader is referred to Druckman and Jackson (2007a) and (2007b). 


\section{Results from pilot studies}

\subsection{Resource use in areas of extreme relative deprivation and affluence}

In this section, selected outputs from LARA are presented to illustrate the type of results on which calculation of the AR-Gini is based. The results are for two contrasting case study Output Areas, chosen to represent extreme deprivation and extreme affluence as described in Section 3.1. The locations of the areas are shown in Table 2. As expected, the results show that the mass of resources used is higher in the extremely affluent case study area and lower in the severely deprived case study area than the mean for England and Wales. This is demonstrated in Figure 3 which compares the weights of 'Household Appliances' and 'Carpets' purchased in the two case study areas with the mean household demand in England and Wales (Druckman et al. 2007).

Figure 3 shows that, in the case of 'Carpets', the resource use in the deprived case study area is $33 \%$ below the mean for England and Wales, whereas for 'Household Appliances' the resource use is $18 \%$ below the mean. In the extremely affluent case study area, resource use due to 'Carpets' is $65 \%$ above the mean for England and Wales, and just 48\% above the mean for 'Household Appliances' (Druckman et al. 2007). This shows that there are more likely to be high levels of inequality with regard to 'Carpets' than for 'Household Appliances'. This analysis looks at extremes of deprivation but gives no information about how equitable the distribution of resource usage is across England and Wales between these extremes. For this task we turn to the AR-Gini.

\subsection{Inequalities in the resource usage of areas}

This section presents pilot Lorenz curves and estimates of the AR-Gini for selected commodities. Figure 4 shows the Lorenz curve for 'Carpets', 'Clothes Washer/Driers', 'Refrigerators, Freezers and Fridge Freezers', and 'Men's and Boys' Garments'. From this we can see that the curves do not intersect and therefore we can conclude that the AR-Gini gives unambiguous ranking of inequalities between these commodities. The Lorenz curves for each commodity are close to the line representing perfect unity. This result is expected as the area basis that has been used to demonstrate the methodology in this paper does not use socio-economically homogenous areas. Lorenz curves based on Output Areas are expected to show greater levels of inequality. 
Table 3 shows the AR-Gini for selected commodities averaged over years 2000/01 to 2003/04. The figures indicate higher inequality for 'Carpets' than for other commodities such as 'Clothes Washer/Driers', and 'Refrigerators, Freezers and Fridge Freezers', and 'Men's and Boys' Garments'; this is in line with the results presented in Section 4.1, which showed a greater disparity for 'Carpets' than for 'Household Appliances'. From this we can conclude that there are more likely to be pockets of deprivation with regard to carpets and household appliances than clothing.

Figure 5 illustrates the use of the AR-Gini to show trends in changes in equity over time. It shows the trend for 'Men's and Boys' Garments' over the study period 1996/7 to 2003/4. This is compared to an area-based expenditure Gini coefficient for 'Total Expenditure', and also to an expenditure Gini coefficient for 'Total Expenditure' calculated on a household basis. The coefficients are indexed to 1.0 at year 1996/7 as the absolute values of Gini coefficients calculated on different bases (area or household) are not directly comparable (Wodon and Yitzhaki 2003). When looking at Total Expenditure the area-based coefficient shows greater variation over time than the household-based coefficient. This could be due to accumulated inaccuracies such as rounding errors in the modelling process; further work is required to investigate this.

The plot shows that the AR-Gini for 'Men's and Boys' Garments' is $27 \%$ lower in the final year of the study than in the first year of the study, implying a significant decrease in inequality in clothing resource use during the years of the study. This is comprised of a steep initial downward trend with a slight small reversal in the final three years of the study. The Consumer Price Index (CPI) for Clothing fell sharply from 163 in 1997 to 116 in 2002 (on 2005=100 basis) and then continued falling, but less steeply, reaching 100 in $2005^{13}$. The fall in CPI reflects an increasing availability of cheaper clothing and is likely to be the reason for lower inequality in this category over time (Allwood et al. 2006). The reasons behind the slight rise in AR-Gini for clothing in the final three years of the study require further investigation.

\footnotetext{
${ }^{13}$ The CPI is available from http://www.statistics.gov.uk/statbase/TSDdownload1.asp. Accessed 30.10 .06
} 


\section{Conclusions}

This paper has described the concepts behind the development of a novel indicator, the AR-Gini, and presented the methodology for its calculation. The AR-Gini is an area-based measure of inequalities in resource use. It can also be used as an indicator of the inequalities in emissions associated with resource use, such carbon dioxide emissions due to energy use. The methodology is capable of estimating inequalities on a life-cycle basis to include resources (and emissions) embedded in consumer products and services. The AR-Gini is calculated using outputs obtained from the Local Area Resource Analysis (LARA) model developed by the University of Surrey, which estimates average household resource use (and associated emissions) in local areas for consumer commodities at high levels of socio-economic and geographical disaggregation. In the paper we present pilot results to illustrate application of the AR-Gini. Future work will include embedded resource use, and a more disaggregated area basis.

The AR-Gini indicates the extent to which there are pockets of deprivation concerning specific resource uses. This can be useful when applied, for example, to food. The problem of 'food deserts' is well known and the AR-Gini can be used to investigate for which specific types of foods (such as meat or dairy products) the problem is most severe. Similarly, the AR-Gini can be used to uncover for which other types of resource use pockets of deprivation are likely to be of concern. For example, the pilot estimations of the AR-Gini reported in this paper indicate higher levels of inequality for carpets than for household appliances and men's clothing. The results also indicate that levels of inequality have fallen in the case of men's and boys' clothing, and this finding is in line with the fall in the Consumer Price Index for clothing. These results illustrate that different levels of inequality are associated with different commodities, and that the AR-Gini is capable of estimating these levels, and their trends.

The primary aim of the AR-Gini is to explore the distribution of resources in order to increase our understanding of area-based resource inequalities. However the AR-Gini does have possible implications for policy. For example, it may be used to model expected outcomes of proposed policy measures. A specific example of this is use of the AR-Gini to model estimated changes in equality due to the introduction of a Supplier Obligation on UK energy companies to reduce their customers' carbon dioxide emissions. For this exercise we would identify the socio-economic characteristics of the types 
of households that would be expected to be targeted by suppliers to reduce their energy use. By using this information in LARA the estimated change in the AR-Gini may be calculated. The dataset produced for LARA is already being used by the Centre for Sustainable Energy (CSE) ${ }^{14}$ for just such a task in a study commissioned by the UK Department of Environment, Food and Rural Affairs (Defra) (Roberts et al. 2007). Extension of this to calculate the AR-Gini to show changes in equality in energy use and associated carbon dioxide emissions that the Supplier Obligation may be expected to bring about is, theoretically, straight forward to carry out and the benefit would be a simple indicator to help rank policy options.

In conclusion, the AR-Gini is an indicator aimed at enhancing our understanding of resource inequalities and their drivers. It could also be used to monitor the distributional impacts of resourcerelated interventions and may help avoid regressive policies. It provides a basis for broadening the debate on food deserts by identifying the extent of "clothing beaches", "appliance wildernesses" and “carpet outbacks"!

\section{Acknowledgements}

The authors would like to thank two anonymous referees for their comments on early drafts of this paper. We also thank Phil Sinclair of the Centre for Environmental Strategy at the University of Surrey for his early contribution to the work. The research was made possible through funding from the EPSRC Sustainable Urban Environment Waste Consortium programme (Grant Number GR/S79626/01), and ESRC Research Group on Lifestyles Values and Environment (RESOLVE) (Grant Number RES-152-25-1004). Data from the 2001 Census are provided by the Commissioned Output Census Service of the Office for National Statistics (Crown Copyright 2005).

\section{Glossary of abbreviations}

AR-Gini Area-based Resource Gini coefficient

GOR Government Office Region

IMD Index of Multiple Deprivation

LARA Local Area Resource Analysis model

OA Census Output Area

\section{References}

Adriaanse, A., S. Bringezu, A. Hammond, Y. Moriguchi, E. Rodenburg, E. Donald Rogich and H. Schütz, 1997. Resource flows: The material basis of industrial economies, World Resources Institute, USA.

\footnotetext{
${ }^{14}$ Centre for Sustainable Energy. http://www.cse.org.uk/
} 
Alexander, C., 2006. "Fluid Households and Object Flows." Warmer Bulletin: Journal for sustainable waste management, Issue 106, Sept. 2006, pp 12-14.(106): 12-14.

Allwood, J. M., S. E. Laursen, C. M. Rodriguez and N. M. P. Brocken, 2006. Well dressed? The present and future sustainability of clothing and textiles in the United Kingdom. Cambridge, UK, University of Cambridge Institute for Manufacturing.

Atkinson, A. B., 1983. The economics of inequality. Oxford, UK, 2nd Edition, Oxford University Press.

Barr, N., 1998. The Economics of the Welfare State. Stanford, USA, Stanford University Press.

Bimonte, S., 2002. "Information access, income distribution, and the Environmental Kuznets Curve." Ecological Economics 41(1): 145.

Bosi, S. and T. Seegmuller, 2006. "Optimal cycles and social inequality: What do we learn from the Gini index?" Research in Economics 60(1): 35.

Boyce, J. K., 1994. "Inequality as a cause of environmental degradation." Ecological Economics 11: 169-178.

Bringezu, S. and Y. Moriguchi, 2002. Material Flow Analysis In: A handbook of Industrial Ecology. R. U. Ayres and W. A. Ayres.(R. U. Ayres and W. A. Ayres) Cheltenham, UK, Edward Elgar.

Clarke, I., A. Hallsworth, P. Jackson, R. de Kervenoael, R. Perez-del-Aguila and M. Kirkup, 2004. "Retail competition and consumer choice: contextualising the "food deserts" debate." International Journal of Retail \& Distribution Management 24(2): 89-99.

Department of Trade and Industry, 2005. Over-indebtedness in Britain: A DTI report on the MORI Financial Services survey 2004. London, UK.

Druckman, A. and T. Jackson, 2007a. The Local Area Resource Analysis (LARA) Model. Concepts, Methodology and Applications. RESOLVE Working Paper Series, University of Surrey, Guildford, UK.

Druckman, A. and T. Jackson, 2007b. Towards a low carbon society: a highly disaggregated model of household energy consumption. 11th European Roundtable on Sustainable Consumption and Production, Basel, Switzerland. 20-22 June 2007.

Druckman, A., P. Sinclair and T. Jackson, 2005. A geographically and socio-economically disaggregated local household consumption model for the UK. 10th European Roundtable on Sustainable Consumption and Production, Antwerp, Belgium, 5-7 October 2005.

Druckman, A., P. Sinclair and T. Jackson, 2007. "A geographically and socio-economically disaggregated local household consumption model for the UK." Journal of Cleaner Production. In press.

Eurostat, 2001. Economy-wide material flow accounts and derived indicators. A methodological guide, Office for Official Publications of the European Union, Luxembourg.

Fernandez, E., R. P. Saini and V. Devadas, 2005. "Relative inequality in energy resource consumption: a case of Kanvashram village, Pauri Garhwal district, Uttranchall (India)." Renewable Energy 30(5): 763.

Goodman, A. and Z. Oldfield, 2004. Permanent Differences? Income and Expenditure Inequality in the 1990s and 2000s. London, UK, The Institute for Fiscal Studies.

Guy, C., G. Clarke and H. Eyre, 2004. "Food retail change and the growth of food deserts: a case study of Cardiff." International Journal of Retail \& Distribution Management 34(2): 72-88. 
Heady, P., P. Clarke, G. Brown, K. Ellis, D. Heasman, S. Hennell, J. Longhurst and B. Mitchell, 2003. Model-Based Small Area Estimation Series No. 2 Small Area Estimation Project Report. London, UK, Office for National Statistics.

Heerink, N., A. Mulatu and E. Bulte, 2001. "Income inequality and the environment: aggregation bias in environmental Kuznets curves." Ecological Economics 38(3): 359.

Herendeen, R. A., 1974. "Affluence and Energy Demand." Mechanical Engineering (October): 18-22.

Hertwich, E., 2006. Accounting for sustainable consumption: A review of studies of the environmental impacts of households' In: The Earthscan Reader in Sustainable Consumption. T. Jackson.(T. Jackson) London, UK, Earthscan.

HM Government, 2005. Securing the future: delivering UK sustainable development strategy. London, UK.

Jackson, T., E. Papathanasopoulou, P. Bradley and A. Druckman, 2006. Attributing Carbon Emissions to Functional Household Needs: a pilot framework for the UK. International Conference on Regional and Urban Modelling, Brussels, Belgium. 1-2 June 2006.

Jacobson, A., A. D. Milman and D. M. Kammen, 2005. "Letting the (energy) Gini out of the bottle: Lorenz curves of cumulative electricity consumption and Gini coefficients as metrics of energy distribution and equity." Energy Policy 33(14): 1825.

Kok, R., H. Falkena, R. Benders, H. C. Moll and K. J. Noorman, 2003. Household metabolism in European countries and cities: Comparing and evaluating the results of the cities Fredrikstad (Norway), Groningen (The Netherlands), Guildford (UK), and Stockholm (Sweden), ToolSust. Center for Energy and Environmental Studies University of Groningen.

Magnani, E., 2000. "The Environmental Kuznets Curve, environmental protection policy and income distribution." Ecological Economics 32(3): 431.

Matthews, E., C. Amann, S. Bringezu, M. Fischer-Kowalski, W. Hüttler, R. Kleijn, Y. Moriguchi, C. Ottke, E. Rodenburg, D. Rogich, et al., 2000. The Weight of Nations: Material outflows from industrial economies. Washington DC, World Resources Institute.

Miller, R. E. and P. D. Blair, 1985. Input-output analysis: foundations and extensions. Englewood Cliffs, New Jersey, USA., Prentice-Hall.

Office for National Statistics. 2001. "Census 2001." Accessed 24.04.06, from http://www.statistics.gov.uk/census2001/pdfs/glossary.pdf.

Office for National Statistics, 2005. Family Spending: A report on the 2003-04 Expenditure and Food Survey. Basingstoke, Hampshire, UK.

Office for National Statistics. 2006. "Geography Policy." Accessed 24.04.06, from http://www.statistics.gov.uk/geography/census_geog.asp\#oa.

Office of the Deputy Prime Minister, 2004. The Indices of Deprivation 2004. London, UK.

Oladosu, G. and A. Rose, 2007. "Income distribution impacts of climate change mitigation policy in the Susquehanna River Basin Economy." Energy Economics 29(3): 520.

Papathanasopoulou, E. and T. Jackson, 2007. "Measuring Fossil Resource Inequality - a longitudinal case study for the UK: 1968-2000." Ecological Economics (submitted).

Rao, J. N. K., 2003. Small Area Estimation. Hoboken, New Jersey, USA, Wiley-Interscience. 
Roberts, S., V. White, I. Preston and J. Thumin, 2007. Assessing the Social Impacts of a Supplier Obligation: A study for Defra. Bristol, UK, Centre for Sustainable Energy.

Rosenblum, J., A. Horvath and C. T. Hendrickson, 2000. "Environmental Implications of Service Industries." Environmental Science and Technology 34(22): 4669 - 4676.

Ruitenbeek, H. J., 1996. "Distribution of ecological entitlements: Implications for economic security and population movement." Ecological Economics 17(1): 49.

Saboohi, Y., 2001. "An evaluation of the impact of reducing energy subsidies on living expenses of households." Energy Policy 29(3): 245.

Scruggs, L. A., 1998. "Political and economic inequality and the environment." Ecological Economics 26(3): 259.

Shaw, H., J., 2006. "Food Deserts: Towards the Development of a Classification." Geografiska Annaler, Series B: Human Geography 88(2): 231.

Stern, N., 2006. Stern Review: The Economics of Climate Change. London, UK, HM Treasury.

Stymne, S. and T. Jackson, 2000. "Intra-generational equity and sustainable welfare: a time series analysis for the UK and Sweden." Ecological Economics 33(2): 219.

Todd, J. and M. Curran, 1999. Streamlined Life-Cycle Assessment: a final report from SETAC North America Streamlined LCA Workgroup, SETAC.

Tol, R. S. J., T. E. Downing, O. J. Kuik and J. B. Smith, 2004. "Distributional aspects of climate change impacts." Global Environmental Change Part A 14(3): 259.

Tukker, A. and B. Jansen, 2006. "Environmental Impacts of Products: A Detailed Review of Studies." Journal of Industrial Ecology 10(3): 159.

UNEP. 2003. "Evaluation of Environmental Impacts in Life Cycle Assessment." Accessed 133.08.07, from http://lcinitiative.unep.fr/default.asp?site=lcinit\&page_id=F511DC47-8407-41E9AB5D-6493413088FB\%20\%20.

Vickers, D., P. Rees and M. Birkin, 2005. Creating the National Classification of Census Output Areas: Data, Method and Results, University of Leeds, UK.

WCED, 1987. Our Common Future. Oxford, UK, OUP.

Weizsacker, E. U. v., A. B. Lovins and L. H. Lovins, 1996. Factor Four: Doubling Wealth, Halving Resource Use - A Report to the Club of Rome. London, UK, Earthscan.

Wodon, Q. and S. Yitzhaki, 2003. "The effect of using grouped data on the estimation of the Gini income elasticity." Economics Letters 78(2): 153. 


\section{List of Tables}

\begin{tabular}{ll}
\hline Table 1. & Comparison of AR-Gini coefficient with conventional Gini coefficient \\
\hline Table 2 & Location of case study areas representing extremes of deprivation and affluence \\
\hline Table 3 & AR-Gini coefficient for selected commodities (2000-04)
\end{tabular}

\section{Figure Captions}

\begin{tabular}{ll}
\hline Figure 1 & LARA system diagram \\
\hline Figure 2 & $\begin{array}{l}\text { Calculation of Gini Coefficient using the Lorenz curve. } \\
\text { Source: Goodman and Oldfield (2004) }\end{array}$ \\
\hline Figure 3 & $\begin{array}{l}\text { Weight of 'Carpets' and 'Household Appliances' purchased in areas of contrasting } \\
\text { relative deprivation, 2000-04. } \\
\text { Source: Druckman et al (2007) }\end{array}$ \\
\hline Figure 4 & Pilot plots of Lorenz curves for selected commodities \\
\hline Figure 5 & Trends in Gini and AR-Gini coefficients (Index 1996/97=1.00) \\
\hline
\end{tabular}


AR-Gini

Gini

(Area Resource Gini)

\begin{tabular}{ll}
\hline Calculated on an area basis & Calculated on a per capita or household basis \\
\hline Calculated on a resource basis & Calculated on a monetary basis \\
\hline
\end{tabular}

Table 1. Comparison of AR-Gini coefficient with conventional Gini coefficient 
Extreme deprivation

00BYFE0010

21UHHX0002

Extreme affluence
L8 0RP

TN225NE

Case study area postcode

Case study area location

(town/Government Office Region)

Liverpool, North West

Uckfield, South East

Source: Druckman et al (2007).

Table 2. Location of case study areas representing extremes of deprivation and affluence 


\begin{tabular}{lc}
\hline Commodity & $\begin{array}{c}\text { AR-Gini Coefficient } \\
(2000-04)\end{array}$ \\
\hline Carpets & 0.085 \\
\hline Clothes Washer/Driers & 0.050 \\
\hline Refrigerators, Freezers \& Fridge Freezers & 0.053 \\
\hline Men's and Boys' Garments & 0.064 \\
\hline (Total Expenditure $*$ & $0.073)$ \\
\hline
\end{tabular}

* This is an area-based expenditure Gini coefficient included for comparison purposes.

Table 3. AR-Gini coefficient for selected commodities (2000-04) 


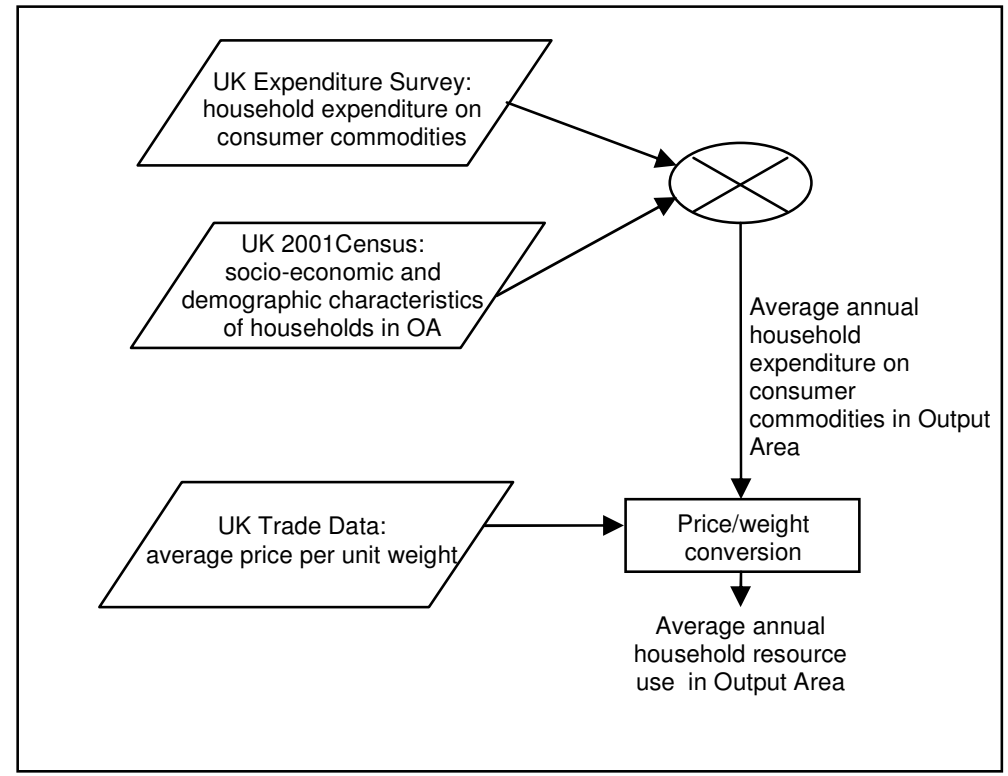

Figure 1. LARA system diagram 


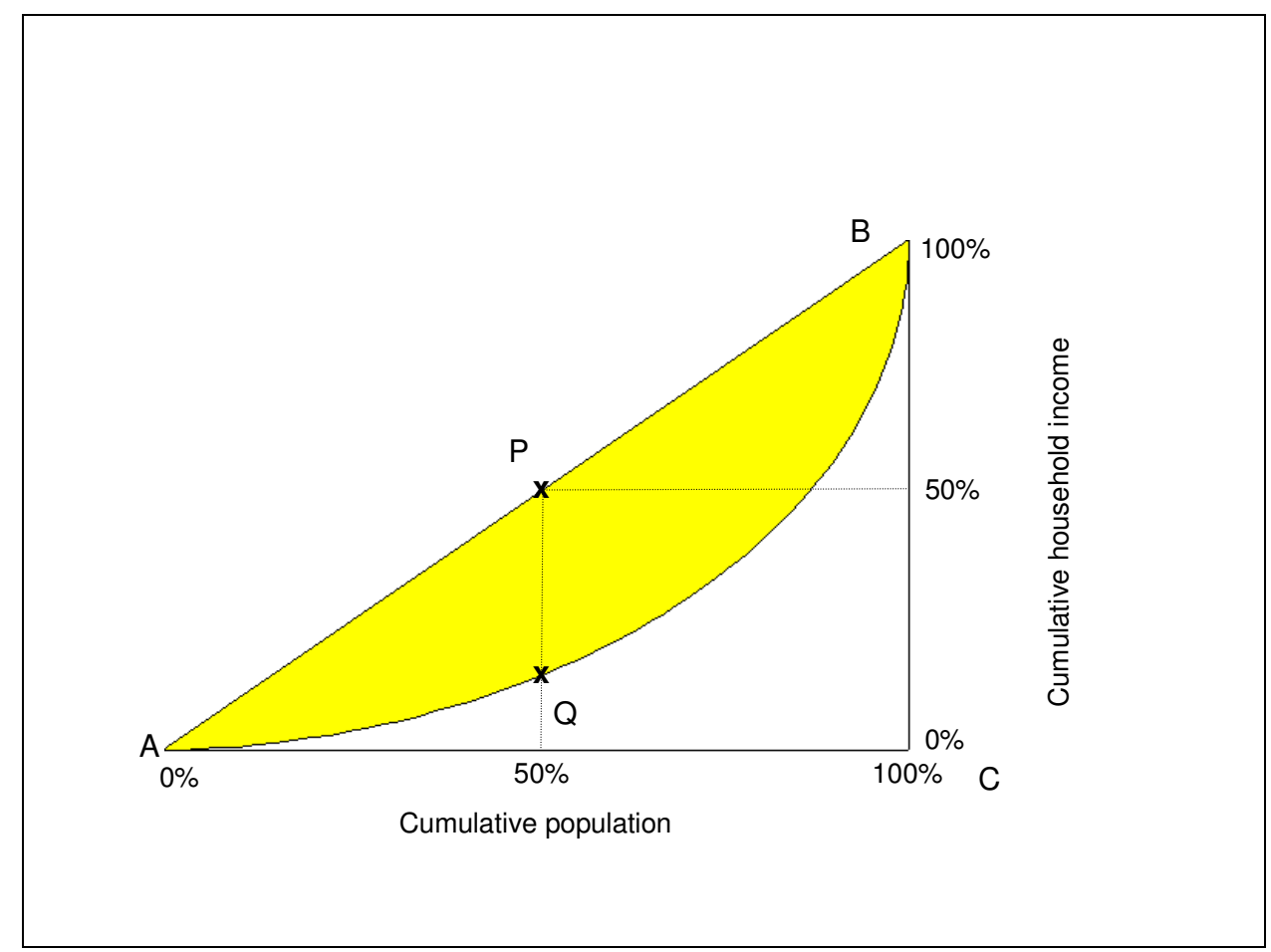

Source: Goodman and Oldfield (2004).

Figure 2. Calculation of Gini Coefficient using the Lorenz curve. 


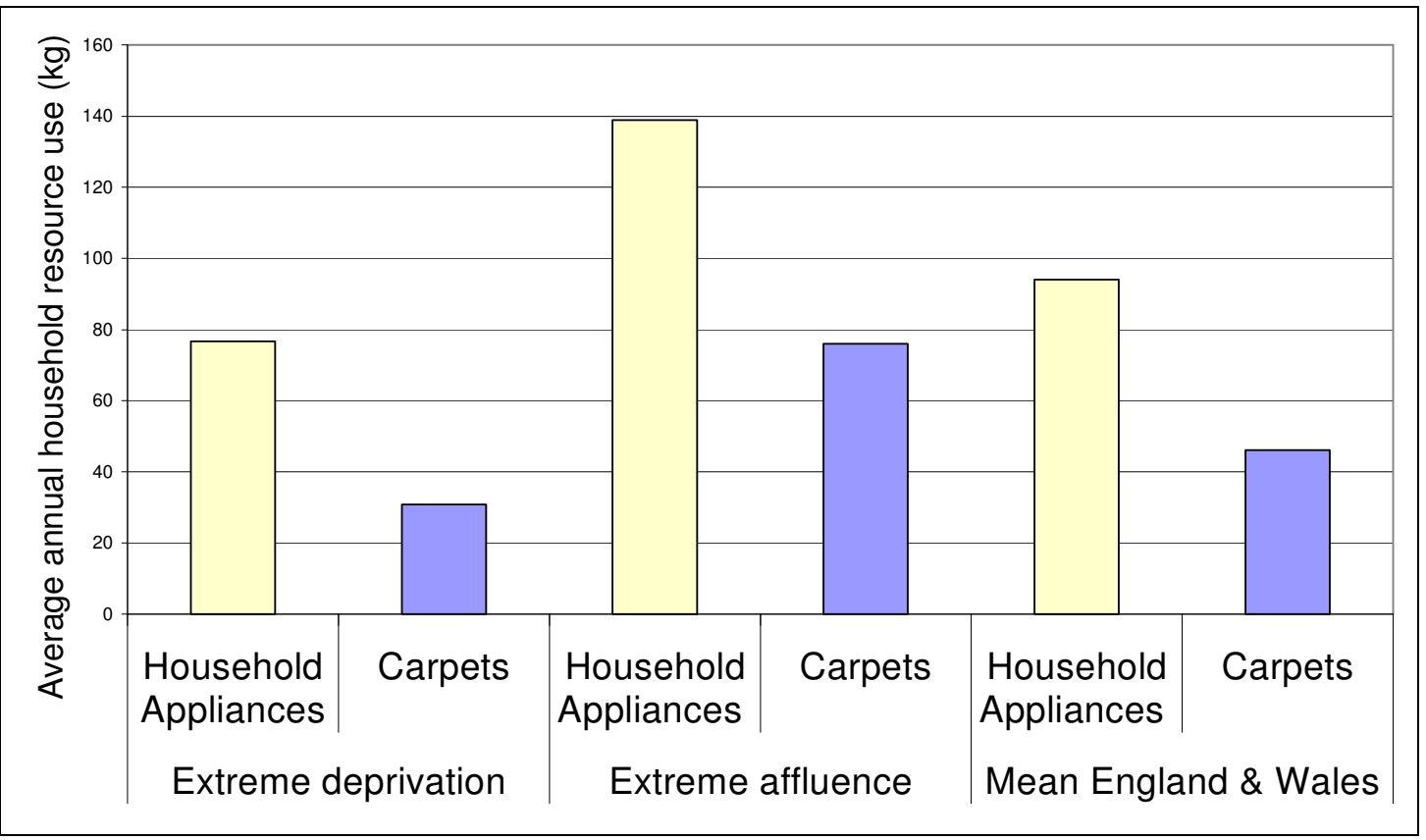

Source: Druckman et al (2007).

Figure 3. Weight of 'Carpets' and 'Household Appliances' purchased in areas of contrasting relative deprivation, 2000-04. 


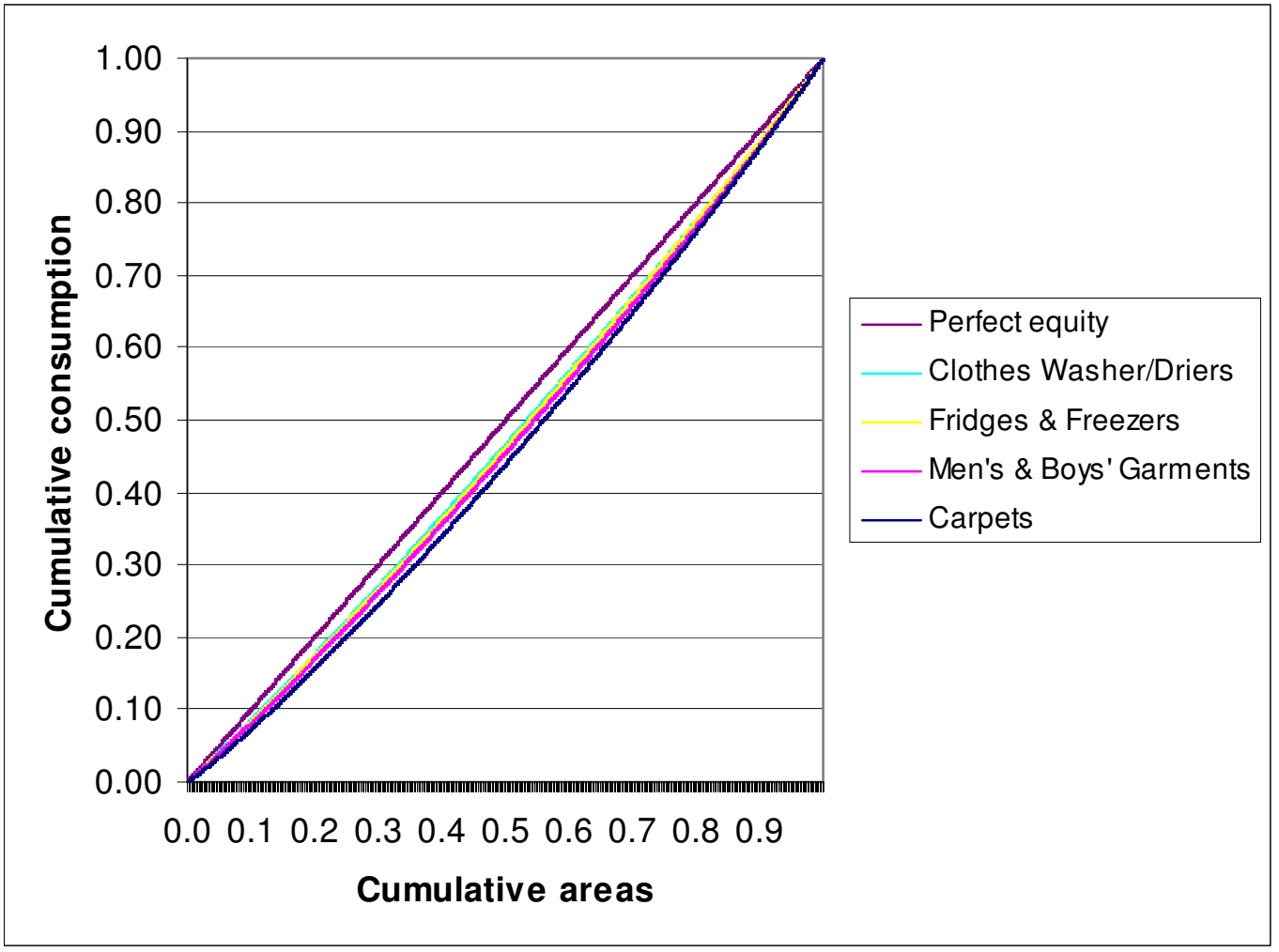

Figure 4. Pilot plots of Lorenz curves for selected commodities 


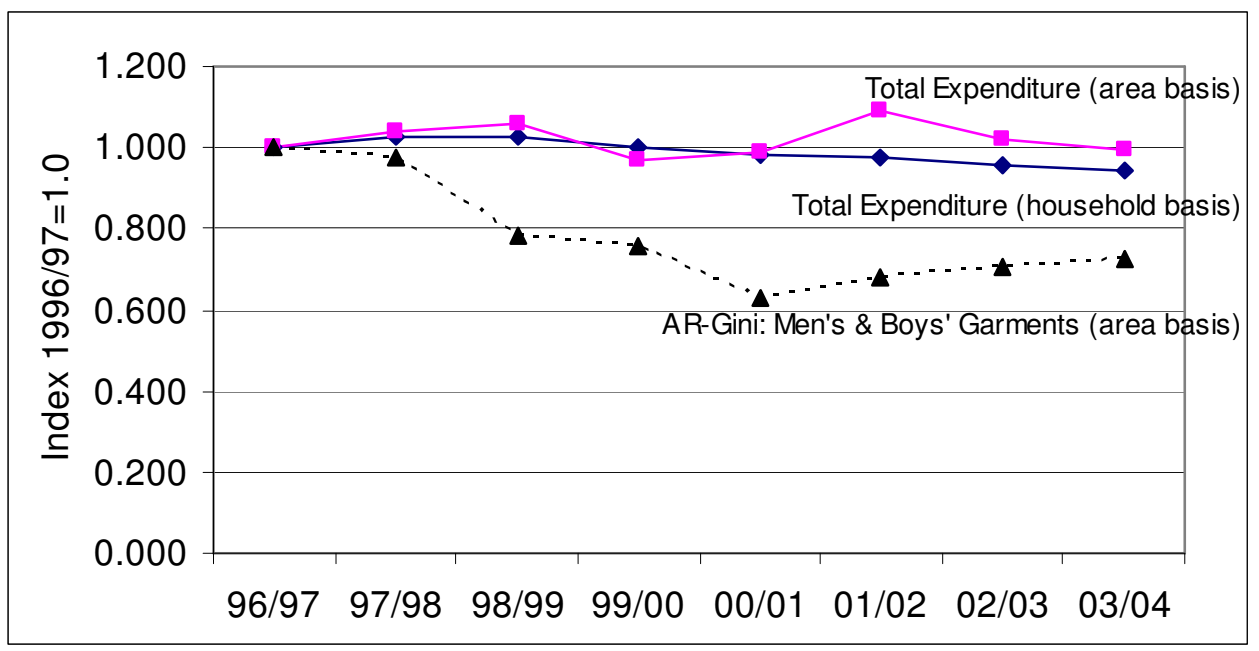

Figure 5. Trends in Gini and AR-Gini coefficients (Index 1996/97=1.00) 